\title{
Climate Smart Agriculture - Awareness of Farm Women
}

\author{
Neela Rani ${ }^{1}$ and Uma Jyothi ${ }^{2 *}$ \\ ${ }^{1}$ Principal Scientist, All India Coordinated Project on Home Science Extension, Professor \\ Jayashankar State Agricultural University, Hyderabad-30, India \\ ${ }^{2}$ Senior Research Fellow, All India Coordinated Project on Home Science-Extension, India \\ *Corresponding author
}

\section{Keywords}

Awareness, Climate change, Farm women, Climate smart agriculture

Article Info

Accepted:

26 August 2020

Available Online:

10 September 2020

\section{A B S T R A C T}

Empowering farmwomen to respond to the challenges posed by climate change is the need of the hour. Climate change and environmental degradation represent a great threat to poverty reduction, gender equality and to achieve the Sustainable Development Goals (SGDs. Its impact is not only on food production but also on health, food security, nutrition, migration, and people's earnings. Awareness, perceptions and knowledge play a key role in shaping individual and collective response to climate change. Understanding gender dimensions of climate change, awareness and knowledge contributes to effective climate change adaptation. Climate-smart agriculture (CSA) is one of the integrative approach to address these interlinked challenges of food security and climate change, clearly aiming at food security, increase productivity and incomes, build resilience to climate change, and reduce emissions from agricultural systems. Farms, crops, livestock aquaculture and Fisheries Management, better resource management as well ecosystem and land management leading to the increase in the resource efficiency and resilience. CSA provide a platform for shared learning and collaboration among all interested Farm women and Farmers. The study explored the awareness levels of the farm women from 6 adopted villages of All India Coordinated Project on Home Science (AICRP -HSc) through questionnaire-based personal interviews involving 100 respondents. Majority of the respondents were farmers with marginal and small land holdings. Findings of the study revealed that most (74) of the respondents are not very well aware of the climate change. Whereas only few (26) of the respondents were aware that deforestation is the main cause for the climate change. Hence the study recommends a requirement for scientists, government and non-government agents and other stakeholders to focus on awareness creation on climate change and mitigating approaches in perception of crop Rotation, drought tolerant varieties, Zero Tillage, Weather Forecasting, Indigenous technologies etc.

\section{Introduction}

"Climate change" is a change which is recognized directly or indirectly to human activity that alters the composition of the global atmosphere (UNFCCC). Agriculture is essentially sensitive to climatic changes and is one of the most vulnerable sectors. Climate change directly affects agriculture production and production efficiency. It affects agriculture in terms of productivity, agricultural practices, environmental effects, 
rural space, and adaptation. Climate change is visibly occurring across the globe, impacting the conditions, experiences, and livelihoods of populations in multiple ways. Unfavorable weather conditions such as delayed monsoon, intermitted dry spells, erratic rainfall and prolonged droughts etc., are the major concern to the farmers.

Climate change is today's most debated environmental issue. It is an important issue because it can affect all aspects of the society and the livelihood of people especially the rural farmers. Main projections for climate change at Global Level: expected growth in greenhouse gases, increase in global surface warming (surface air temperature change)by $1.1-6.4{ }^{\circ} \mathrm{C}$, rise in sea levels between 18 and $59 \mathrm{~cm}$, oceans will become more acidic ,hot extremes, heat waves and heavy precipitation events will become more frequent, there will be more precipitation at higher latitudes and less precipitation in most subtropical land areas, tropical cyclones (typhoons and hurricanes) will become more intense, larger peak wind speeds and heavier precipitation associated with ongoing increases of tropical sea surface temperatures. climate change is the biggest threat to agriculture in India but still the farmers are not fully aware of climate change and its indicators, causes, and impacts. Sarkar and Padaria in West Bengal reported that only 38 per cent of the farmers had heard about climate change and a large number are not aware of the phenomena of climate change. Farmers experienced the changing climatic conditions in their life but they are still not aware about the term climate change. Adewale and Owolade found that 87.5 percent of farmers have heard about climate change whereas Sogani reported that communities in the mountain areas of Uttarakhand are well aware that weather is changing.

Climate Change does not affect everyone in the same way. Men and women are affected differently. Their responses to the impacts of climate change also differ, especially when it comes to safeguarding their food security and livelihoods. Although women are important food producers and providers, they have limited access to and control of resources, on the one hand. On the other hand, because of their central role in agriculture, women are great agents of social change.

Climate change demands new approaches to agriculture: farmers' practices will need to change to adapt to and mitigate the effects of changing conditions. Addressing gender inequality is a key to ensuring this outcome. Initiatives need to ensure that women are included in climate change mitigation and adaptation activities and strategies designed to enhance food security and livelihoods. To date, however, there has been little focus on how men and women mitigate risks and adapt to challenges brought about by climate change. Climate-smart agriculture (CSA) is an approach to ensure food security, increase productivity and incomes, build resilience to climate change, and reduce emissions from agricultural systems.

Agricultural crops in the Rangareddy district are cotton, maize, sugar cane, ground nut, red gram, etc. Administrative wise, the district is divided into 37 sub-districts, 24 towns and 870 villages. Rangareddy district has been the meeting ground for the fusion of various civilizations, religions, races, cultures, languages and traditions with the twin cities of Hyderabad and Secunderabad as its core. Castor, Jowar, Pulses and Ground Nut are the main crops grown in the RR District.

\section{Materials and Methods}

The study was conducted in Maheswaram and Moinabad mandals of the Rangareddy district, Southern Dry Zone of Telangana. Based on the existence of high range of variability in the rainfall and temperature (since 40 years), 
the district mandals were selected. Accordingly, the blocks/Mandals selected were Maheswaram and Moinabad Mandals. From each of the selected taluks five villages were selected randomly. By applying simple random sampling technique 100 respondents were selected for the study. The data collected through a detailed interview schedule employing personal interview method. The responses were scored, quantified, categorized and tabulated using statistical methods like frequencies, percentage, mean, standard deviation and correlation.

Carter (1997) pointed out that farmer's smallscale farmers suffer most because of their dependence on rain-fed agriculture and lack of capacity to diversify. Stamm et al., (2000) observed that $88 \%$ of respondents had low level of awareness and knowledge about climate change.

Terry (2005) estimated that, due to climate changes earth's temperature increased by $1.5^{\circ} \mathrm{F}$ during the 20 th century. There is a rise in sea level by 7 inches in California since 1850 and also shrinking snow pack - spring runoff decreased by 10 per cent. Sujit and Padaria (2010) revealed that people were more aware about increase in diseases due to climate change was the major perceived risk by the respondents in agriculture, animal husbandry.

Sellers \& Henderson (1990) opined that participants in Australia were also concerned about a possible change and they expressed decrease in quality of life due to environmental changes. Rupan Raghuvanshi, et al., (2017) in her study opined that the increasing industrialization, overpopulation and deforestation' were perceived by farmers to be the main causes of climate change. Sinha and Sinha (1984) in their study conducted on attitude of farmers towards soil conservation programme revealed that majority of the farmers $(80 \%)$ had medium level of attitude and the rest were distributed under high(12\%) and low(8\%) attitude categories.

\section{Results and Discussion}

Majority of the (48\%) of the members are Middle (36-50 yrs.) aged, thirty-seven (37\%) percent are young (18-35yrs) and fifteen percent $(15 \%)$ are Upper middle (50 yrs. and above) aged. From this it is evident that majority of the respondents were in the age group of 18 years to 50 years who are actively involved in farming. 37 Percent of farmers belong to OBC category, 23 percent belongs to General Category and rest are from SC (29\%) and ST (11\%). It is interesting that 70 percent respondents are illiterates, while 8 percent of respondents have studied up to Middle schooling and Up to class $\mathrm{x}$. while only negligible $(2 \%)$ amount of respondents have passed their HSLC. Hundred percent of respondents are $(100 \%)$, married. Farming is the major occupation for 77 percent of the respondents while 20 percent of them are daily wage earners. Only 3 percent are in some sort of services (Table 1-5).

\section{Type of family}

India is renowned for the Joint family structure as majority of the rural families predominantly dependent on Agriculture where it involves family labour. But there has been a gradual disintegration of the joint family system and emergence of 'nuclear family'. The study reported 92 percent families as Nuclear families, reflecting the rise of the nuclear families even in rural Indian agricultural families. Only 5 percent of the respondents reported to be in the joint family.

\section{Size of family}

The study also reported the shrink of family size from large (3\%), to small $(83 \%)$ and medium only (14\%) households. 
Table.1

\begin{tabular}{|c|c|c|c|c|}
\hline SI No. & Characteristics/Attributes & Category & Frequency & Percentage \\
\hline \multirow[t]{3}{*}{1} & \multirow[t]{3}{*}{ Age } & Young( 18-35yrs.) & 37 & 37.00 \\
\hline & & Middle(36-50 yrs.) & 48 & 48.00 \\
\hline & & $\begin{array}{l}\text { Upper middle ( } 50 \text { yrs. } \\
\text { and above) }\end{array}$ & 15 & 15.00 \\
\hline \multirow[t]{4}{*}{2} & \multirow[t]{4}{*}{ Caste } & Gen & 23 & 23.00 \\
\hline & & $\mathrm{OBC}$ & 37 & 37.00 \\
\hline & & ST & 11 & 11.00 \\
\hline & & $\mathrm{SC}$ & 29 & 29.00 \\
\hline \multirow[t]{9}{*}{3.} & \multirow[t]{9}{*}{ Education } & Illiterate & 70 & 70.00 \\
\hline & & $\begin{array}{l}\text { Can read and } \\
\text { write }\end{array}$ & 3 & 03.00 \\
\hline & & Primary & 1 & 01.00 \\
\hline & & Middle & 8 & 08.00 \\
\hline & & Up to class $x$ & 8 & 08.00 \\
\hline & & HSLC passed & 2 & 02.00 \\
\hline & & $\begin{array}{l}\text { Higher secondary } \\
\text { passed }\end{array}$ & 6 & 06.00 \\
\hline & & Graduate & 2 & 02.00 \\
\hline & & Post Graduate & 0 & 00.00 \\
\hline \multirow[t]{4}{*}{4.} & \multirow[t]{4}{*}{ Marital status } & Married & 100 & 100.00 \\
\hline & & Unmarried & 0 & 0.00 \\
\hline & & Widow & 0 & 0.00 \\
\hline & & Divorcee & 0 & 0.00 \\
\hline \multirow[t]{11}{*}{5.} & \multicolumn{4}{|l|}{ Occupation } \\
\hline & \multirow[t]{5}{*}{ i) Main occupation } & Farming & 77 & 77.00 \\
\hline & & Service & 3 & 03.00 \\
\hline & & Farm allied & 0 & 0.00 \\
\hline & & Business & 0 & 0.00 \\
\hline & & Daily wage earner & 20 & 20.00 \\
\hline & \multirow[t]{5}{*}{ ii) Subsidiary occupation } & Farming & 20 & 20.00 \\
\hline & & Service & 9 & 09.00 \\
\hline & & Farm allied & 4 & 04.00 \\
\hline & & Business & 9 & 09.00 \\
\hline & & Daily wage earner & 58 & 58.00 \\
\hline \multirow[t]{3}{*}{6.} & \multirow[t]{3}{*}{ Type of family } & nuclear & 92 & 92.00 \\
\hline & & joint & 5 & 05.00 \\
\hline & & extended & 3 & 03.00 \\
\hline \multirow[t]{3}{*}{7.} & \multirow[t]{3}{*}{ Size of family } & Small & 83 & 83.00 \\
\hline & & Medium & 14 & 14.00 \\
\hline & & large & 3 & 03.00 \\
\hline \multirow[t]{3}{*}{8.} & \multicolumn{4}{|l|}{ Organizational participation } \\
\hline & i) Type of membership & Member & 97 & 97.00 \\
\hline & & Office bearer & 3 & 03.00 \\
\hline
\end{tabular}




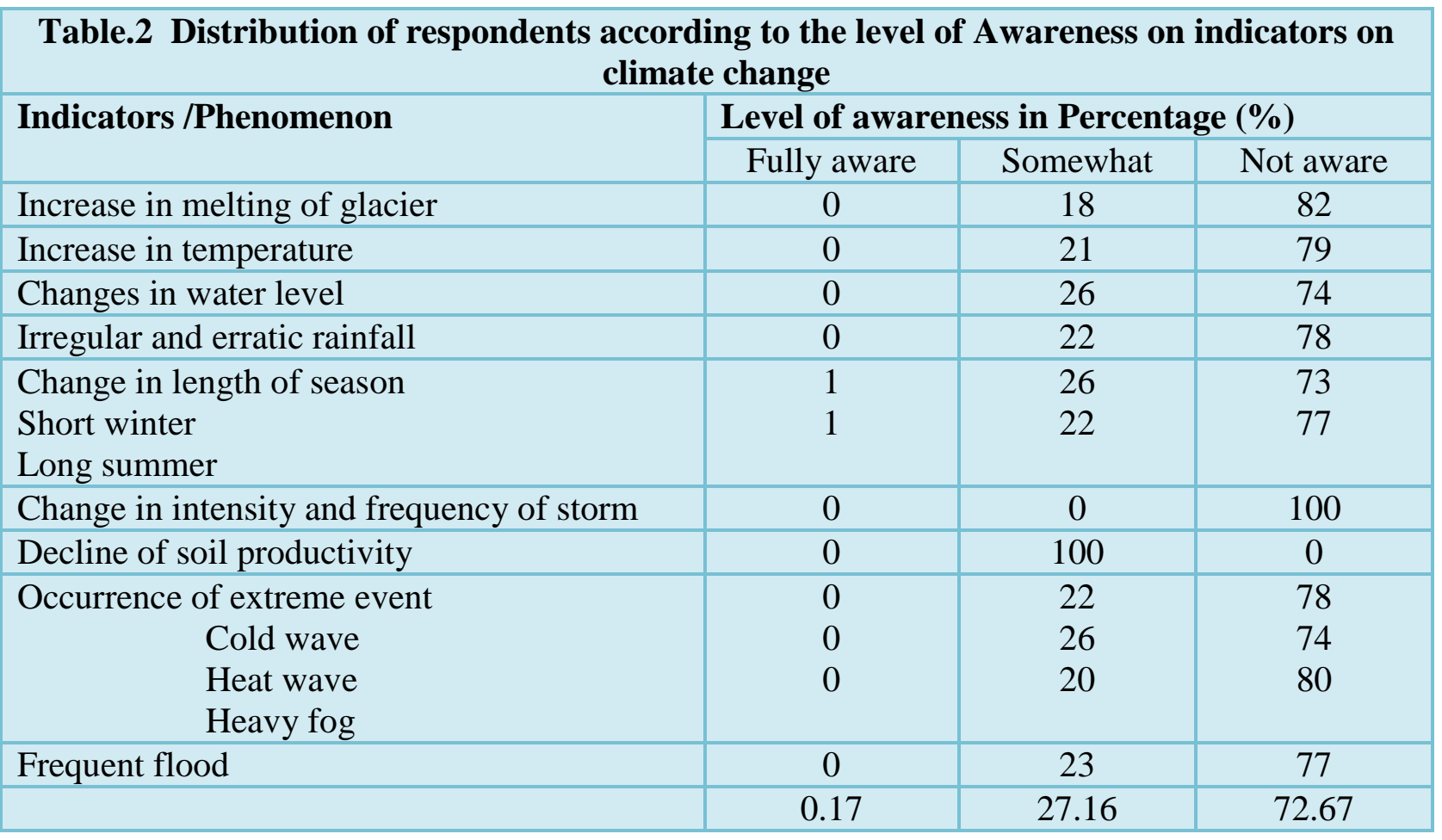

\section{Table.3 Distribution of respondents according to the Awareness on climate variables influencing production}

\begin{tabular}{|l|r|r|}
\hline Statement & Aware (\%) & Not Aware (\%) \\
\hline Changes in farming system in present climate condition & 100 & 0 \\
\hline Increase of disease of crop & 100 & 0 \\
\hline Increase in infestation of pest due to climate change & 92 & 8 \\
\hline Awareness about the ill effect of pesticides & 81 & 19 \\
\hline
\end{tabular}

\begin{tabular}{|l|l|l|l|}
\hline \multicolumn{4}{|c|}{$\begin{array}{c}\text { Table.4 Distribution of respondents according to the level of Awareness on Causes of } \\
\text { Climate Change }\end{array}$} \\
\hline \multirow{2}{*}{ Statement } & \multicolumn{2}{|c|}{ Level of awareness } \\
\cline { 2 - 4 } & Fully aware (\%) & Somewhat (\%) & Not aware (\%) \\
\hline Increase in number of vehicles & 0 & 26 & 74 \\
\hline Overpopulation & 0 & 26 & 74 \\
\hline Industries and factories & 0 & 27 & 73 \\
\hline Use of Pesticides & 0 & 23 & 77 \\
\hline Burning of fossils and farm waste & 0 & 26 & 74 \\
\hline Use of electrical appliances & 0 & 19 & 81 \\
\hline Pollution & 0 & 22 & 78 \\
\hline Global Warming & 0 & 21 & 79 \\
\hline Natural Disaster & 0 & 22 & 78 \\
\hline Rapid urbanization & 0 & 20 & 80 \\
\hline Any other & 0 & 0 & 0 \\
\hline
\end{tabular}




\begin{tabular}{|c|c|c|c|c|}
\hline \multicolumn{5}{|c|}{$\begin{array}{l}\text { Table.5 Distribution of respondents according to the Level of Awareness on climate } \\
\text { variable influencing production }\end{array}$} \\
\hline \multirow[t]{2}{*}{ Incidence } & \multicolumn{4}{|c|}{ Degree of change in percentage $(\%)$} \\
\hline & Extreme (\%) & $\begin{array}{l}\text { Moderate } \\
(\%)\end{array}$ & Negligible (\%) & None (\%) \\
\hline Drought & 26 & 74 & 0 & 0 \\
\hline Flood & 26 & 64 & 8 & 2 \\
\hline Increased temperature & 100 & 0 & 0 & 0 \\
\hline Change in growing season & 100 & 0 & 0 & 0 \\
\hline
\end{tabular}
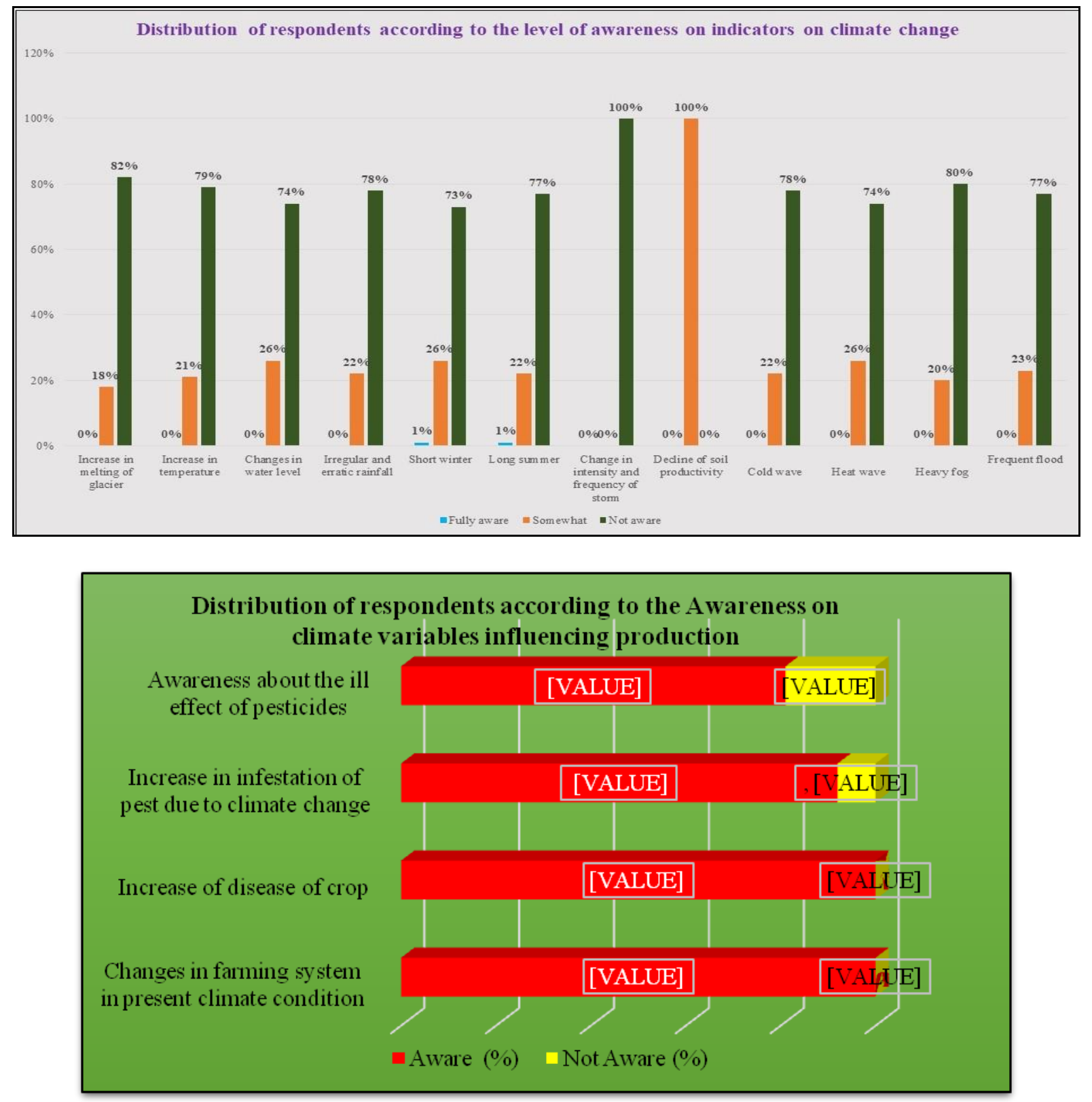


\section{Distribution of respondents according to the level of Awareness causes of climate change}

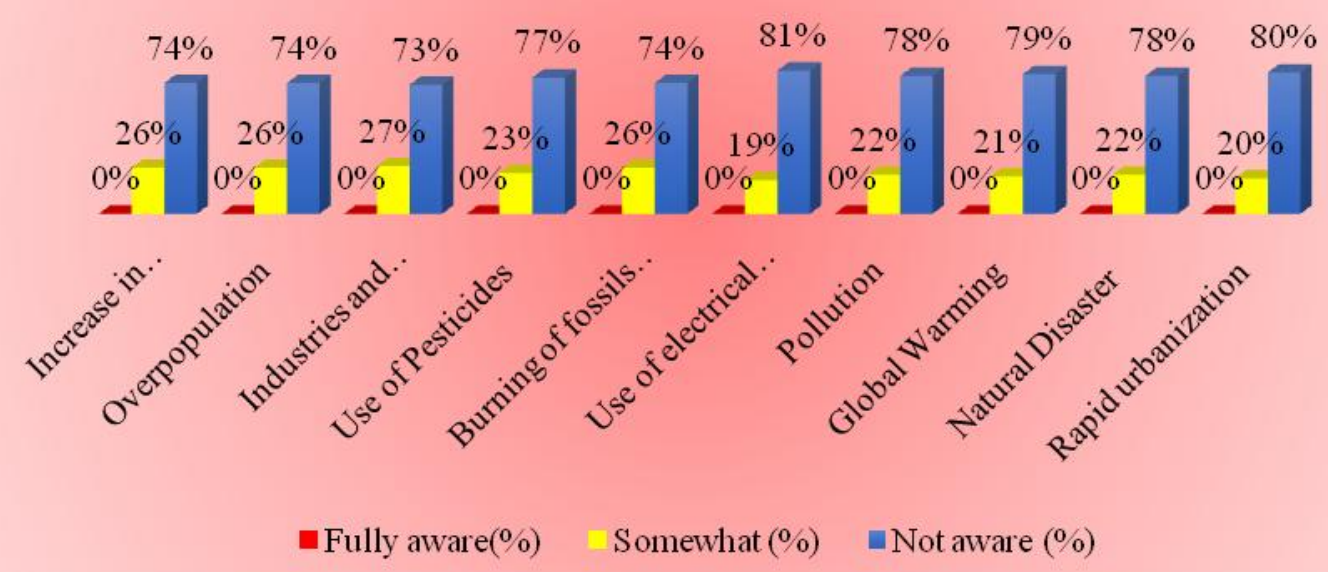

\section{Organizational participation}

It is clearly evident that majority $97 \%$ of the respondents were having Organizational participation among which some are participating as Office bearer (3\%) in the selfhelp groups.

Data on awareness of farm women regarding climate change situation specific coping strategies reveals that, great majority of the farm women $(82 \%)$ were not aware of the Increase in melting of glacier, Increase in temperature $(79 \%)$, Changes in water level (74\%), Irregular and erratic rainfall $(78 \%)$ Change in length of season Short winter and Long summer (73\% and $77 \%)$. Occurrence of extreme event Cold wave (78\%) Heat wave (74\%) Heavy fog $(80 \%)$.

But as the farmers, the entire $100 \%$ reported that they are somewhat aware of the decline in the soil productivity, with regard to change in intensity and frequency of storm. Total $100 \%$ are not aware of it. As the data sample area is in Telangana State, which is located in Deccan Plateau with semi-arid tropical area, the people are not exposed to storms or cyclones unlike coastal belt.

Distribution of respondents according to the Awareness on climate variables influencing production divulges that $100 \%$ of the farm women respondents were aware on changes in farming systems in present climatic conditions and increase of diseases of crops. But only $92 \%$ of the samples are aware of increase in inflation of pest due to climate change - as there is severe drought in Maheswaram and Moinabad blocks of Ranga Reddy District crops are severely affected with pests and disease. Viz. Maize, cotton, rice, vegetables. A great majority of the farm women respondents $(81 \%)$ had awareness about ill effects of pesticides.

Distribution of respondents according to the level of awareness on Causes of Climate Change, $74 \%$ of the farm women respondents are not aware of causes for climate change. Increase in number of vehicles, over population $(74 \%)$ use of pesticides $(77 \%)$ burning of fossils and farm waste) 74\%) Use of electrical appliances (81\%) pollution (78\%) Global warming (79\%) Natural Disaster (78\%) rapid urbanization (80\%) etc. Only very few percentage i.e. less than $20 \%$ of the respondents are aware of them. 
The level of awareness on climate change variable influencing production and its degree of change with the incidence of drought was reported moderate $74 \%$, and extreme with $24 \%$. Incidence of flood was reported with $64 \%$ moderate, $26 \%$ extreme and change in growing season for increase in temperature $100 \%$ reported extreme degree of change, as they could perceive the decline in production and productivity during this season of time.

In conclusions, the outcomes of this study indicates that majority of the respondents belongs to low level of educational category with low level of farming experience and medium land holding of 3-5 acres' agricultural lands. Less than half of the farmers 43.33 per cent of respondents belongs to low level of Innovative proneness category. As the data sample area was in Telangana State, which is located in Deccan Plateau with semi-arid tropical area, the people are not exposed to storms or cyclones unlike coastal belt, the farm women reported that they are somewhat aware of decline in the soil and its productivity with climate change. Majority of the farm women were not at all aware of the increase in melting of the glaciers. While coming to the awareness about climate variables that influences production reveals that farm women were aware on changes in farming systems in present climatic conditions and increase of diseases of crops. A great majority of the farm women had awareness about ill effects of pesticides and increase in inflation of pest due to climate change - as there is severe drought in Maheswaram and Moinabad blocks of Ranga Reddy District crops are severely affected with pests and disease. Viz. Maize, cotton, rice, vegetables. Once the level of awareness on causes of Climate Change was studied it was revealed that the bulk farm women are not aware of causes for climate change whereas less than $20 \%$ of the respondents are aware of rapid urbanizations. The awareness on climate change variables influencing production and its degree of change with the incidence of drought was reported to be moderate.

\section{References}

Parry, M.L.; Carter, T.R. An assessment of the effects of climatic change on agriculture. Clim. Chang. 1989, 15, 95-116.

Rupan Raghuvanshi, Mohammad Aslam Ansari, Amardeep. A Study of Farmers' Awareness About Climate Change and Adaptation Practices in India. International Journal of Applied Agricultural Sciences. Vol. 3, No. 6, 2017, pp. 154-160. doi: 10.11648/j.ijaas.20170306.13

Sujit, S. and Pandaria, R. N., 2010, Farmer's Awareness and Risk perception zabout climate change in coastal ecosystem of West Bengal. Ind. Res. J. Extn. Edu. $10(2)$

Sellers, H. A., 1990., Australian Public Perception of the Greenhouse Issue. Climatic Change, 17: 69-96.

Sinha, H. S. P. and Sinha, A. K., 1984, A study on attitude of farmers oh chotanagpur towards soil conservation programme. Ind. J. Extn. Edu., 20(3\&4):9-18.

Stamm, K., Clark, F. and Eblacas, P., 2000, Mass communication and public understanding of environmental problems: the case of global warming. Public Understanding of Science. 9(3): 219-237.

Terry Dressler., 2005, Global climate change. Issues, trends, outlook. Community Advisory Council, Air Pollution Control Officer December 14.

\section{How to cite this article:}

Neela Rani and Uma Jyothi. 2020. Climate Smart Agriculture - Awareness of Farm Women. Int.J.Curr.Microbiol.App.Sci. 9(09): 3509-3516. doi: https://doi.org/10.20546/ijcmas.2020.909.435 